\title{
Malaysian Administrative Building Responsive Design Approach
}

\author{
Hazrina Haja Bava Mohidin, Alice Sabrina Ismail \\ Department of Architecture, Faculty of Built Environment, \\ Universiti Teknologi Malaysia, Skudai 81310, Malaysia
}

hazrinahaja@gmail.com

\begin{abstract}
The main purpose of this paper is to elucidate on the study of state administrative building in Malaysia by describing the design built form and it adaptation towards the surrounding. Using multiple case study approach, Perdana Putra and Parliament Malaysia were chosen as prominent case studies with emphasis on form and space studies. Since this paper formulates new ways to describe on state administrative building design, it uses interpretive paradigm and semiotics as the methodological approach to study the relationship between building design and sustainable aspects. This paper is of value for practicing architects and society as it offers new insights by formulating design approaches in designing public architecture in Malaysia.

Administration architecture; form and space study; Parliament; Perdana Putra

eISSN 2514-751X @ C 2018. The Authors. Published for AMER ABRA cE-Bs by e-International Publishing House, Ltd., UK. This is an open-access article under the CC BY-NC-ND license (http://creativecommons.org/licenses/bync-nd/4.0/). Peer-review under responsibility of AMER (Association of Malaysian Environment-Behaviour Researchers), ABRA (Association of Behavioural Researchers on Asians) and $c E-B s$ (Centre for EnvironmentBehaviour Studies), Faculty of Architecture, Planning \& Surveying, Universiti Teknologi MARA, Malaysia DOI: https://doi.org/10.21834/aje-bs.v3i10.317
\end{abstract}




\subsection{Introduction}

Like any other forms of architecture, administrative building carries a wide selection of vocabulary especially from the aspect of design characteristics. This paper investigates the built form composition of the federal administrative architecture in Malaysia. Present administrative architecture often portrays eclectic style that incorporates Greek, Roman, Persian and Moorish architecture instead of referring to the local identity and values. This is vital because state administrative buildings are often treated as the symbol of political power and built as an icon to promote the city (Riza et al., 2012). Today's society needs to understand the role of administrative architecture and how the building should represent the identity of the country. This study is of importance for practicing architects and designers to understand that the present examples of administrative architecture may not necessarily be the best example of administrative architecture to symbolize Malaysia as a multiracial society and a democratic country. This paper focuses on documenting sustainable design characteristics on administrative architecture to produce suitable guidelines in designing better administrative building with consideration to sustainable characteristics in the future.

\subsection{Literature Review}

\section{Definition of sustainable administrative architecture}

When explaining on administrative architecture in this study, it is important to conceptualize it as the highest institution in the country. A government administrative architecture accommodates the work of lawmakers to perform all related administrative activities. The building is usually located at the capital of the country and regarded as the capitol building (Vale, 2008). Administrative buildings were built not only to symbolize the power and authority of the government but also to portray the identity of the society at country, states, region, district and communal level to the outside world apart from serving as a place to run the seat of the government. At country level, the most important type of administrative building is the Prime Minister's Office and the Parliament Complex (Vale, 2008). Since the focus of this paper is to highlight on the issue of sustainable design it is worthwhile to define the meaning of sustainable architectural characteristics next.

Administrative buildings are categorized under Non-Residential Existing Building (NREB) by the Green Building Index (GBI) rating system. Within this category, there are five fundamental principles to be observed. First, optimize site potential in which the location, orientation (Husin et al., 2012), and landscaping together with proper site selection, consideration of reuse or rehabilitation of existing buildings is considered. Second, optimize energy use by finding ways to reduce energy load, increase efficiency, and maximize the use of renewable energy sources within the building. Third, optimize building space and material use. In this sense, the building should use materials that can minimize life-cycle environmental impacts such as global warming, resource depletion, and human toxicity (Mahdavinejad et al., 2012). Fourth, enhance indoor environmental quality of a building by using appropriate ventilation, suitable lighting and temperature control system. Fifth, optimize operational and maintenance practices during the preliminary design phase till building 
completion stage (Zainordin et al., 2012). However, for the benefit of this paper, the focus of discussion will only be involving setting, spatial organization and form design (façade and detailing, structural organization as well as usage of materials) to produce better administrative building design in the future.

\subsection{Methodology}

The administrative building acts as medium of communication and production of meaning. Semiotics, being the most suitable method for this reason will use architectural elements; form and space that acts as the basis of this study. By doing so, this research will undergo direct observation as its data collection method and research strategy.

\subsection{Research Methdology.}

Semiotics, in its most basic definition as termed by Cheshmehzangi (2012) along with other notable scholars, is the study of signs. The founder of semiotics; Ferdinand Saussure together with scholars such as Barthes, Peirce, Gottdiener and Dougherty provide the lineage of today's semiotics. Semiotics started with a dyadic notion of the signifier and the signified by Saussure. Being in the literature field, his theory claims that the signifier is the word or sound while the signified is the thought resulting from the word. Saussure's model of sign creates the basic understanding of how signs work; however, it focuses more on the denotation rather than at the connotation. It lacks description of necessary contributing phenomena namely, socio-cultural experience, and surrounding context. The theory of semiotic was later developed by other scholar such as Roland Barthes and claimed that semiotics exist in a triadic notion. He claimed that the systems of signification (relationship between the signifier and signified) are multileveled structures which not only contain denotative signs but also connotative signs when particular cultural codes are ascribed to these signs (Barthes 1988). The first (denotative) order (or level) of signification, therefore is seen as primarily representational and relatively self-contained. The second (connotative) order of signification reflects 'expressive' values which are attached to a sign. In the third (mythological or ideological) order of signification, the sign reflects major culturally-variable concepts underpinning a particular worldview. By understanding this, one will be able to decode and 'read' the meaning of the material culture, which in this sense is architecture. Architecture can be fitted into the triadic notion of understanding semiotics as it includes the relationship of the signifier and the signified in multilevel structure. Therefore, for the benefit of this paper, Barthes' theory of socio-semiotics is adapted to help to describe and define the meaning of administrative architecture as a meaningful 'sign'. Data collection, will involve direct observation of several chosen indicators which includes the analysis of form and space, focusing on façade analysis, structural detailing and placement and setting, as well as spatial organization analysis. Each of these indicators will be discussed in table 1.

\subsection{Method of data collection}

Direct observation is beneficial to the study because administrative buildings chosen for this 
study are restricted in its political nature. Using two indicators established, the theoretical framework chosen to support the study is discussed in the table below.

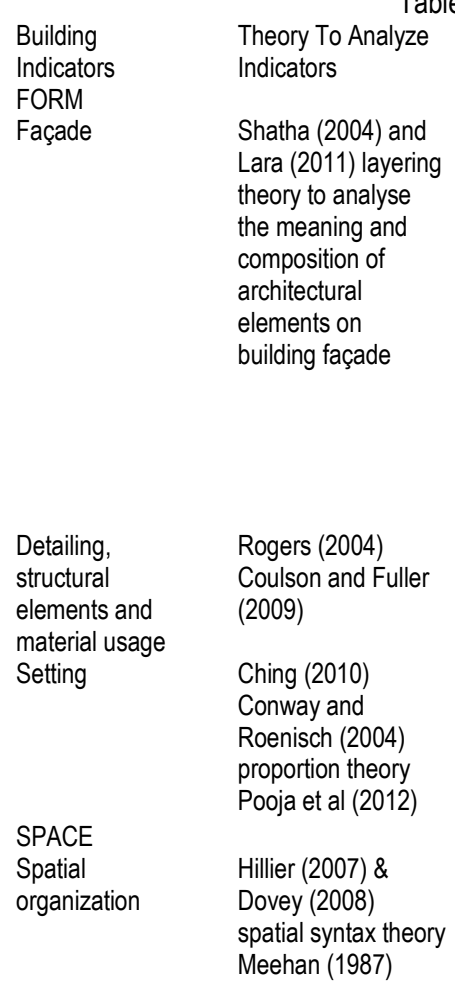

Table 1: Method of data collection

Process

Use layering system is to identify elements of form with the

following steps:

Layer 1: the main form

Layer 2: additional built form

Layer 3: basic primary elements

Layer 4: additional and secondary elements

Layer 5: constructive and decorative details

Layer 6: entire range of stylistic features

-Clarify the basic structure, to enhance the articulation of building façade focusing on architectural morphological elements, identify additional elements juxtaposed and within the façade as well as identify the facade geometrical organization.

Observe and identify architectural elements-portray the usage of natural materials

Three building elements to be observed: Roof, Wall and Floor, and everything in between.

Analysis of building placement and setting from blue print drawings and site observation by identifying the levelling, orientation of the building and land contour, contextual elements within the building setting and landscape. Also observe low carbon activity; reducing motorized vehicle usage, promote walkability etc.

Analyse the floor plan by identifying the entry point and movement pattern within the interior spaces referring to blue print drawings and direct observation

Observation on interior sustainable qualities and its relationship with the exterior spaces to create a low carbon environment which utilizes lower mechanical energy consumption ( Ismail, 2008)

Promoting natural lighting and natural ventilation by passive design approach (Rasdi, 2010)

(Source Author)

\subsection{Results and Discussions}

\subsection{Background study}

\subsubsection{Parliament Complex, Lake Perdana, Kuala Lumpur}

Parliament Complex sits majestically on a hill facing the Lake Perdana, located in the central region of Kuala Lumpur. It has a two part design; the tower and the podium building. The 
Podium building act as the main component of the two providing space for discussion and conference to take place. The podium building is three stories in height and was connected to the tower building via two bridges as seen in figure 1(a) while the tower building is composed of 18 stories office building. The whole composition of the podium building and the tower building sits on a 16.2 acre land, surrounded by vast greeneries and natural habitat.
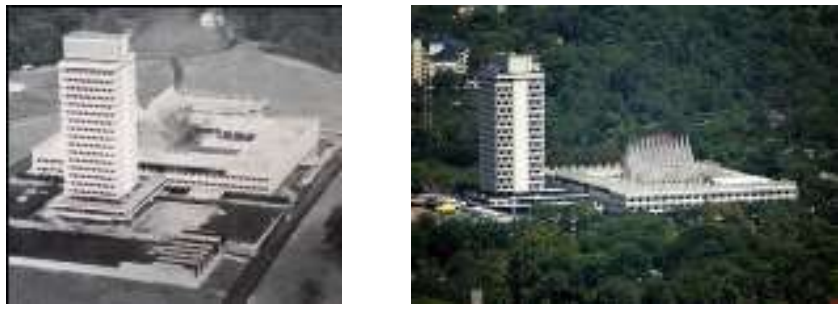

Figure 1: (a) Parliament in the 1960's (b) Parliament as seen today (Source: PWD archive)

The overall design and construction was done by the Public Works Department and most of the ideas were initiated by the architect; Sir Ivor Shipley and Tunku Abdul Rahman himself. Shipley proposed the building to be constructed using new and advance technology in construction to speed up the process as the country was in dire need to own a Parliament Complex of its own. It was noted by Kien (2007) that Shipley tried to design the building in a functional and simplistic language. He also incorporated appropriate design motifs as well as climatic adaptability features to further enhance the functionality of the building. The next section will discusses on the modern administrative building to represent Malaysia's image in the late 20th century.

\subsubsection{Perdana Putra, Putrajaya}

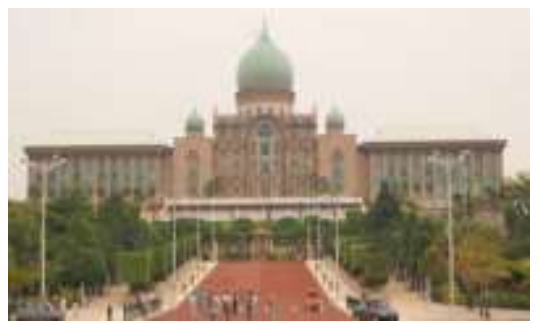

Figure 2: Perdana Putra

(Source: PWD archive)

Completed in 1999 on a 5 acre land and cost RM270 million with only $10 \%$ imported materials incorporated into the design due to the 1997/1998 economic crisis, Perdana Putra was built to complement the federal administrative territory of Putrajaya. All the consultants were 
locally handpicked and the principal architect who was in charge of the building was Ar. Ahmad Rozi Abd Wahab from AQIDEA. Perdana Putra continued to be occupied until today with three Prime Ministers accommodating it.

\subsection{Architectural Analysis}

\subsubsection{Parliament Complex, Lake Perdana, Kuala Lumpur}

\subsubsection{Form- façade}

When describing the façade, the three most important part of the building; roof, body and base must be observed. The roof of the building can be seen to have a variation from being flat at the tower building while the other is peaked and highly sloped on the podium building. The body of the building comes in uniformity where the overall facade is consistently outlaid with an adaptive design feature which dominates the overall view of the building. The base, runs continuously above ground level below this said design feature. The building, be it the tower building or the podium building, is covered thoroughly with this design feature. This feature acts as an envelope to the building as it covers and protects the building while being one meter away from the main glass walls. The design is carried through consistently in size and regularity. The dominance of the facade may be seen on its body where it brings out the character of the building sustainable feature. The facade layering which can be seen recessing from the windows making the building very shady. Most of the windows are full height to allow natural sunlight to lit the office building while having no direct sunlight nor glare into the building.

Table 2: Layering tabulation of Parliament Complex Malaysia

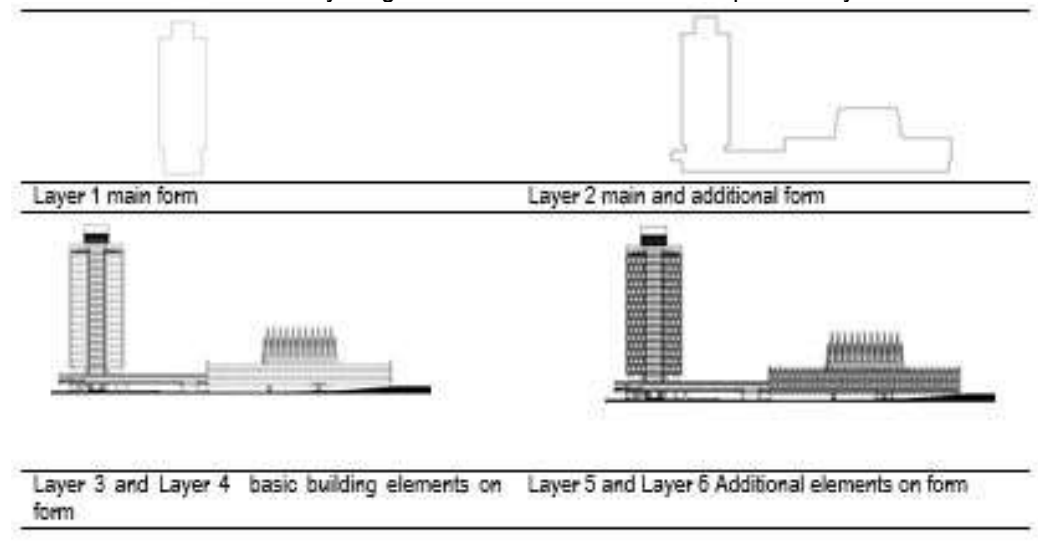

(Source: Author)

\subsubsection{Form- structural and detailing}

There were special technologies applied during the construction stage of the building as 
proposed by the architect who designed Parliament. Grid system and modular system were applied on the construction of the building (Kien, 2007). This helped to reduce duration of construction which therefore reduced manpower as well as cost and construction essential. Construction materials were mostly built in-situ. They also used IBS during this period of time to rapidly enhance the production of buildings (Bari et al, 2012). Materials used were mostly brought in from overseas as well as local building materials. Most of the interior elements such as decorative features on doors, windows and wall panels-incorporated wood carvings and motifs used local timber.

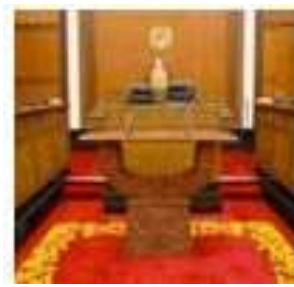

(a)

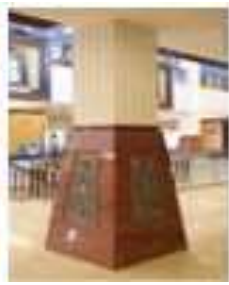

(b)

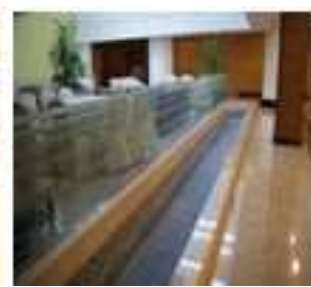

(c)

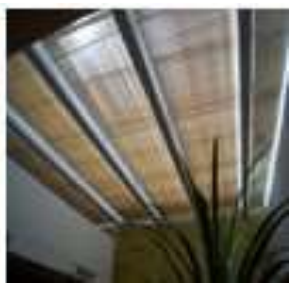

(d)

Figure 3: (a) Dewan Negara (b) Detailed Column (c) Water element (d) Skylight (Source: Author)

\subsubsection{Form- placement and setting}

The Parliament Complex sits on a sloppy hill at the heart of Kuala Lumpur. Based on figure 4 below, it is evident that the placement of Parliament Complex is easily accessed by motorized vehicles. Although this is the case, the entire built up is surrounded in a natural setting; maintained with greeneries overlooking a lake. It is also built on North-West orientation which makes the building naturally shaded away from direct sunlight and glare. Based on observation of the form in its original setting, the building is built on hilly and high level topography.

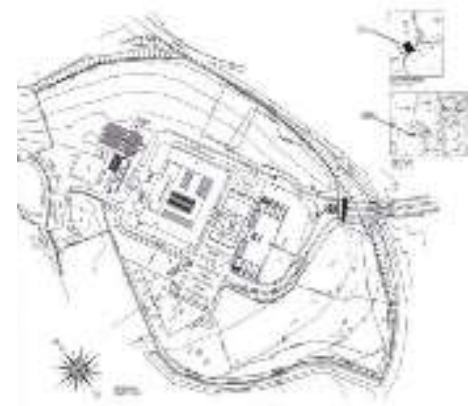

Figure 4: Site plan of Parliament (Source: Author)

\subsubsection{Space}

Based on the building program obtained from the parliamentary, the cabinet meets on 
Monday to Thursday. This occurs at the podium building which operates four times a week. Due to this, Parliament complex is organized in a spatial-clustered manner where spaces are segregated according to specific functions. Most of the spaces are open planned, hence pocketed spaces are minimized. Double volume spaces in the parliament allow better air flow. This results to minimum usage of mechanical system and artificial lighting as the building is sufficiently lit during the day.

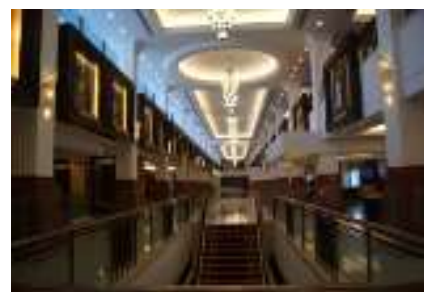

(a)

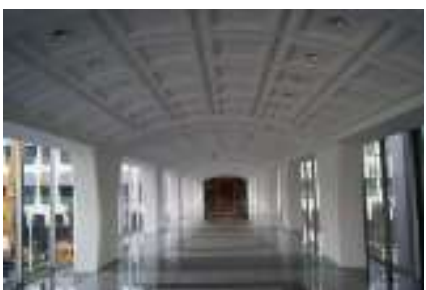

(b)

Figure 5: (a) Double volume spaces (b) Full height windows

(Source: Author)

\subsubsection{Perdana Putra, Putrajaya}

\subsubsection{Form- façade}

Table 3 Layering tabulation of Perdana Putra

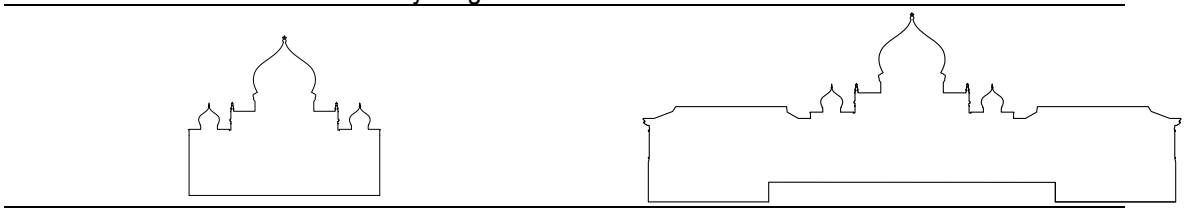

Layer 1 main form with no hierarchy Layer 2 main and additional form

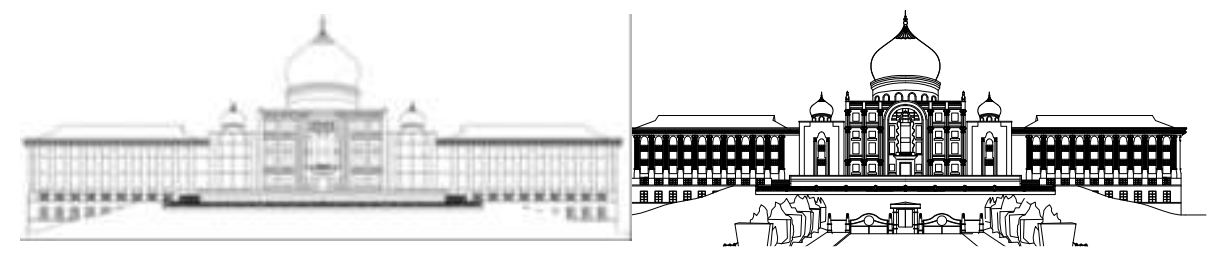

Layer 3 and Layer 4 basic building Layer 5 and Layer 6 Additional elements on elements on form form

(Source: Author)

Table 3 shows the façade layering of Perdana Putra which divides the exterior façade into three sections; the roof, wall and base level, which are arranged in a hierarchical manner. It 106 
is seen as though the large green dome dominates the whole outlook of the building and the pitched roof acts as supporting architectural element to the building. Most of the windows are full height windows and are heavily decorated with stained glass and arches. The whole building could be seen as having consistently arranged roman columns which gives a little recessed on the façade.

\subsubsection{Form- structural and detailing}

$80 \%$ the construction materials used for Perdana Putra is made out of stone. Materials were $90 \%$ obtained locally (Perbandanan Purajaya, 2001). It is also the intention of the patron and the architect to have a solid blend of the building and the natural surroundings. The walls on the other hand are made of granite and stained glass on the exterior of the building. Some parts of the building are decorated with wrought iron motifs.

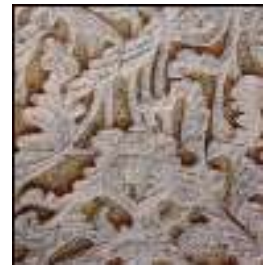

(a)

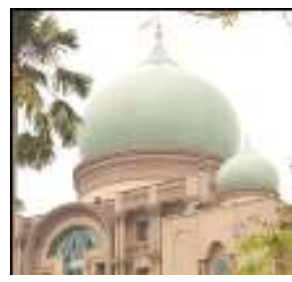

(b)

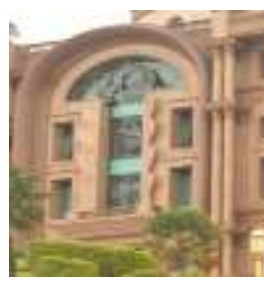

(c)

Figure 6: (a) Stone granite (b) Green fiber-glass dome (c) Wrought iron grill and detailing (Source: Author)

\subsubsection{Form- placement and setting}

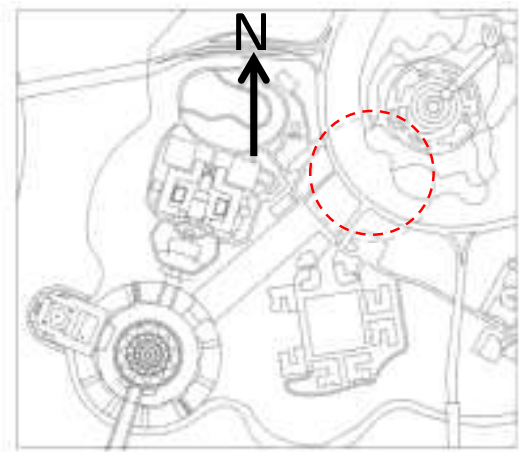

Figure 7: Location Plan of Perdana Putra (in the red circle)

(Source: Author)

Perdana Putra is located in the middle of a planned city. It is placed on a hill, higher than other buildings surrounding it. It overlooks a public square as well as the Putra Mosque. 
Through the plans, Perdana Putra has high accessibility to public amenities. It is reachable by the society and only a walking distance away. However, Perdana Putra cannot be freely accessed. It is rich in greeneries and surrounded by natural elements. It is naturally shaded from direct sunlight as it faces south west (refer to fig. 7).

\subsubsection{Space}

Perdana Putra has a ringy syntax as all the spaces are interrelated to one another. All the blocks are connected via the inner courtyards. Although there are multiple entry to the building, Perdana Putra is a private building. Its arrangement signifies compartmentalization therefore; more mechanical system is needed to run the building. It is plausible though when observing the Perdana Putra and realized that there are so many natural elements being incorporated to the design of spaces on the exterior of the building. There are water elements and courtyard as well as greeneries surrounding the building. In order to maintain security within the building, the spaces are not designed in an opened manner. This is evident as there are many layers within the spaces of the building itself to restrict people from entering the deeper end of an important space as it is believed that the most important place should be located out of reach (Puspitasari et al., 2012). Therefore, more energy is required to penetrate into pocketed space as well as differently compartmentalized spaces.

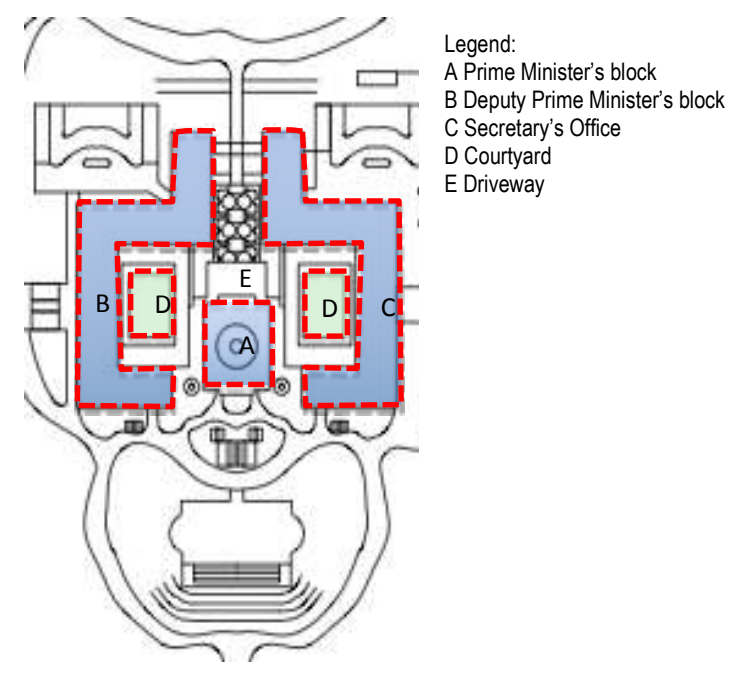

Figure 8: Interior spaces of Perdana Putra (Source: Author)

\subsection{Discussion}

Both buildings have the potential of having sustainable design approach adapted on either 
the form or space of the building in terms of orientation of the building as well as choice of material of construction, while there has been a slight difference on the sustainable responsive feature of these buildings. The table below prevails the similarities and differences between these two buildings. Prior to design analysis done earlier, it is clearly shown that the Parliament had more awareness in adaptive environment where the design of the building tried to pull sustainable feature as well as aesthetical value into one single design element. The parliament complex was able to portray sufficient evident of adaptive facade design as well as structural and detailing, placement and setting and spatial organization.

Parliament Complex
-variation of flat and pitched roof
-uniformity in façade design (used as
structure, aesthetic as well as
environmental adaptation (shading) and
maintenance.

IBS construction using modular and grid system

Cast in-situ

Minimize time, cost and labor

mostly using concrete as the main material material

imported and local materials

on a hill and sloppy, sits next to a lake

easily accessed by motorized vehicles

away from communal facilities

North-West orientation

Passive barrier

Open planned

Operates according to function of the spaces

Spaces are naturally lit

Water feature and skylights

Table 4: Tabulation of findings

\section{Features}

Façade

\section{Structural \& \\ Detailing: \\ Method of \\ construction}

material

Placement \& Setting

Spatial organization

.

\section{Perdana Putra}

variation of domed and pitched roof large windows with no shading added large roman columns creates recessed on the facade

a product of government information transfer program

using up to date construction methods

using granite, wrought iron, glass and stones

materials are mostly obtained locally

on a hill, next to a lake

many entry point but not easily accessed

near to public facilities such as the mosque

South-West orientation

High fence, active barrier

Compartmentalized spaces

Operates according to function of the spaces

Spaces are naturally lit

Courtyards and water features

(Source: Author)

\subsection{Conclusion}

From the laid out research on the comparative study on two prominent administrative architecture; the Parliament Complex and Perdana Putra, it can be said that they are clear differences and similarities that could locate the idea of sustainable design approach embedded within these buildings. We started off by getting to know the background information of each building so as to grasp a better understanding of the building and later to 
link with the production of design. Each building portrays architectural elements evident on their design approaches that could be the basic of understanding on how the study could investigate the responsiveness towards the surrounding of the building. Therefore, by understanding this value, we can conclude that the design of each building has their own special characteristics that build up the identity of Malaysian administrative architecture after achieving independence and together they render a unique composition of architectural styles creating broad variety architectural richness. Nevertheless sensitiveness towards sustainable values are much vital as it will produce more robust and long lasting building that can sustain throughout centuries.

\section{Acknowledgement}

The authors would like to thank the MOHE and Universiti Teknologi Malaysia (UTM) for ERGS grant (vot: 4L041) that supported this research.

\section{References}

Bari, N. A. A., Abdullah, N. A., Yusuff, R., Ismail, N., \& Jaapar, A. (2012). Environmental Awareness and Benefits of Industrialized Building Systems (IBS). Procedia-Social and Behavioral Sciences, 50, 392-404.

Barthes, R. (1988). The semiotic challenge. Oxford: Basil Blackwell.Chandler, D. (2007). Semiotics: the basics. Routledge.

Ching, F. D. (2010). Architecture: Form, space, and order. Wiley. com.

Cheshmehzangi, A. (2012). Identity and public realm. Procedia-Social and Behavioral Sciences, 50, 307-317.

Hillier, B. (2007). Space is the machine: a configurational theory of architecture.

Husin, S. N. F. S., \& Harith, Z. Y. H. (2012). The Performance of Daylight through Various Type of Fenestration in Residential Building. Procedia-Social and Behavioral Sciences, 36, 196-203.

Kien, L. C. (2007) Building Merdeka: Independence Architecture in Kuala Lumpur, 1957- 1966. Kuala Lumpur: Galeri Petronas.

Mahdavinejad, M., \& Mansoori, S. (2012). Architectural design criteria of socio-behavioral approach toward healthy model. Procedia-Social and Behavioral Sciences, 35, 475-482.

Mohidin, H. H. B., \& Ismail, A. S. (2014, February). Historical development of administration architecture in Malaysia (15th-21st century). In IOP Conference Series: Earth and Environmental Science (Vol. 18, No. 1, p. 012089). IOP Publishing.

Puspitasari, P., Djunaedi, S. A., \& Putra, H. S. A. (2012). Ritual and Space Structure: Pilgrimage and Space Use in Historical Urban Kampung Context of Luar Batang (Jakarta, Indonesia). Procedia-Social and Behavioral Sciences, 36, 350-360.

Putrajaya Holdings Sdn. Bhd, \& Pusat Pentadbiran Kerajaan Persekutuan (Malaysia). (2001). Appreciation of the 
Mohidin, H.H.B., \& Ismail, A.S. / Asian Journal of Environment-Behaviour Studies (ajE-Bs), 3(10) Sep / Oct 2018 (p.99-111)

Architecture \& Interior Design of the Office of the Prime Minister of Malaysia. Putrajaya Holdings.

Riza, M., Doratli, N., \& Fasli, M. (2012). City Branding and Identity. Procedia-Social and Behavioral Sciences, 35, 293-300.

Rogers, W. (2004). Frank Lloyd Wright's "Organic Architecture": An Ecological Approach in Theory and Practice. Imaginatio Creatrix, 381-390. Shahoran Bin Johan Ariffini (2003): Putrajaya, Malaysia, Australian Planner, 40:3,4042.

Shatha, M. (2004). Local identity of modern Amman-Jordan: a perceptual approach towards identifying an intersubjective and shared architectural schemata. Urban design international, 9(3), 119-131.

Vale, J. Lawrence (2008) Architecture, Power, and National Identity. London and New York: Routledge.

Zainordin, N. B., Abdullah, S. M. B., \& Baharum, Z. B. A. (2012). Light and Space: Users Perception towards Energy Efficient Buildings. Procedia-Social and Behavioral Sciences, 36, 51-60. 